\title{
Impact of PSS and STATCOM Devices to the Dynamic Performance of a Multi-Machine Power System
}

\author{
Ghazanfar Shahgholian \\ Department of Electrical \\ Engineering, Najafabad Branch \\ Islamic Azad University \\ Najafabad, Isfahan, Iran
}

\author{
Esmaeil Mardani \\ Smart Microgrid Research Center \\ Najafabad Branch \\ Islamic Azad University \\ Najafabad, Isfahan, Iran
}

\author{
Arman Fattollahi \\ Smart Microgrid Research Center \\ Najafabad Branch \\ Islamic Azad University \\ Najafabad, Isfahan, Iran
}

\begin{abstract}
This paper studies the impact of leveraging both static synchronous compensator (STATCOM) and power system stabilizer (PSS) on multi-machine power systems. Considering a standard IEEE 9-bus test power network, classic and intelligent controllers are applied to achieve the desirable system performance. Simulated tests show the usefulness of STATCOM on network power quality in terms of voltage profile. In addition, it is shown that it can significantly improve the damping oscillations of synchronous generator under normal and abnormal network conditions. As shown, the PSS also contributes to improving the synchronous generator parameters. It is also observed that using intelligent controllers with STATCOM and PSS leads to a better performance relative to the classic controllers.
\end{abstract}

Keywords-power quality; intelligent controller; PSS; STATCOM; neuro; fuzzy; ANFIS

\section{INTRODUCTION}

The mission of network managers, manufacturers and distributors of electrical energy, is to deliver the highest possible quality of electrical power and ensure maximum reliability $[1,2]$. In order to achieve such goals, comprehensive information and studies of the power network are required. In normal working conditions, various parameters are important. These include the bus voltage level, the loss of active network, freeing capacity increase of network load, etc. [3, 4]. In critical situations such as sudden withdrawal of large loads, symmetrical and asymmetrical short circuit faults, etc., the situation is more complex. At first, network instability (increase in power angle and the frequency oscillation amplitude) must be prevented and parameters such as voltage fluctuations, the frequency and power angle have to be gradually returned to the desired level $[5,6]$. Figure 1 shows different techniques to damp power oscillation. Generally, FACTS controllers can be divided into four major groups as shown in Figure 2: series controllers such as TCSC and SSSC, shunt controllers such as SVC, STATCOM and STATCOM with energy-storage system, combined series-shunt controllers such as UPFC and TCPS, and combined series-series controllers such as IPFC [7-16]. In power production and transmission, FACTS devices are considered highly important and have been studied in several researches $[8,9]$. To reduce active power losses and to raise the voltage, the placement of reactive power injection $[10,11]$ and FACTS devices controller $[12,13]$, has been considered.

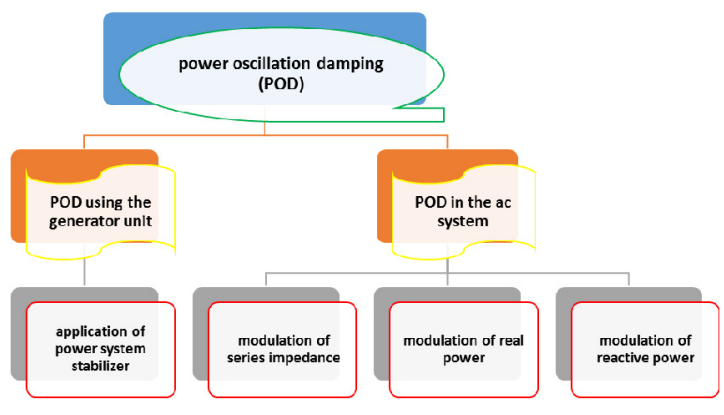

Fig. 1. Strategies to damp power oscillations

Parallel FACTS devices such as STATCOM and SVC [14, 15] have been considered for the supply of reactive power, intense voltage drop compensation and sustained improvement in severe transients whereas FACTS devices such as TCSC and SSSC series have been considered for dynamic stability improvements [16, 17]. However, the high costs of construction and installation of FACTS devices is always to be considered. The Power System Stabilizer (PSS) element is undeniable and very effective $[18,19]$. This equipment is used in production units with synchronous generators, and a significant portion of the risks to the network is eliminated or significantly reduced. In this context, there have been many studies on the impact of PSS on power oscillation damping and frequency $[20,21]$. This equipment as well as other power network controllable equipment has been implemented with various classic and nonlinear controllers [22, 23].

In this paper, the 9-bus and 3-mashine power system is considered as a test network. STATCOM and PSS devices are considered in several positions under normal and abnormal conditions (a three-phase short circuit fault that caused voltage drop, frequency swinging and power angle swinging in 
generating units). A classic PI controller and a neuro-fuzzy controller optimized by ANFIS are employed to control the equipment in each of the above scenarios. Simulations are performed in MATLAB and results are shown and discussed for each scenario.

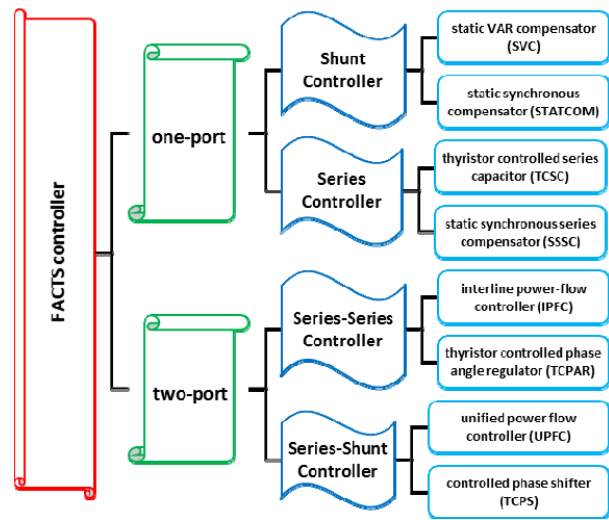

Fig. 2. Classification of FACTS devices

\section{SYSTEM UNDER STUDY}

The IEEE 9-bus standard system consists of 3 synchronous machines with IEEE type-1 exciters as shown in Figure 3. There are 12 buses, 6 transformers and 3 constant impedance loads. It contains 6 lines connecting the bus bars in the system with the generator connected to network through step-up transformer at $230 \mathrm{kV}$ transmission voltage. The total load demand is $315 \mathrm{MW}$ and $115 \mathrm{MVAR}$. For this power system generator, lines and load parameters are given in [24].

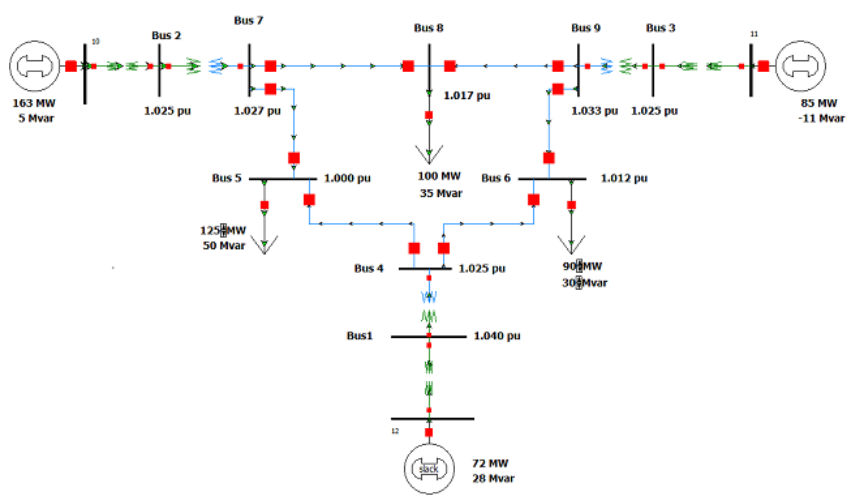

Fig. 3. System under study

\section{SIMULATION RESULTS}

\section{A. Normal Conditions}

The network is simulated based on the results of load flow analysis. The results of the network simulation in the initial state (without STATCOM and PSS) are given in Figures 4 and 5. AS shown in Figure 4, bus 5 voltage is lower than all buses voltage, so the STATCOM is placed at bus 5 .

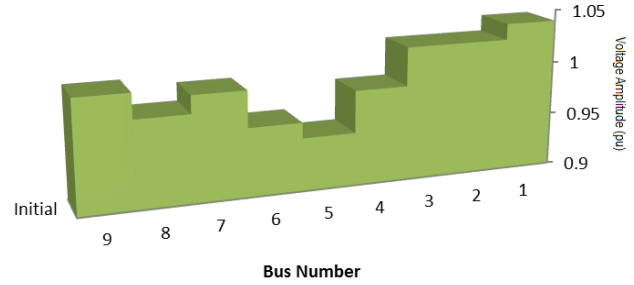

Fig. 4. Voltage buses in the initial state (without PSS and STATCOM)
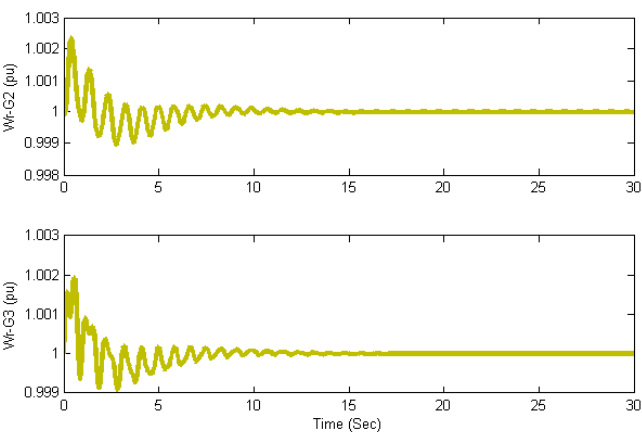

Fig. 5. Angular velocity of generators 2 and 3 according to time (without PSS and STATCOM and the controller)

\section{B. STATCOM Placement in Bus 5}

In this section the PI controller is used, to control the STATCOM device in order to achieve the desired voltage (1.02 $\mathrm{pu})$ at bus 5, and the optimal ratio controller $(\mathrm{KP}=92.2$ and $\mathrm{KI}=9.1$ ) are obtained using a GA. Results of are shown in Figures 6 and 7. With the presence of STATCOM at bus 5, in addition to the voltage on the bus already reaching to $1.02 \mathrm{pu}$, the rest of the buses voltage (except PV generator buses) are in a better mode than before. Also, improvement in angular velocity damping is achieved.

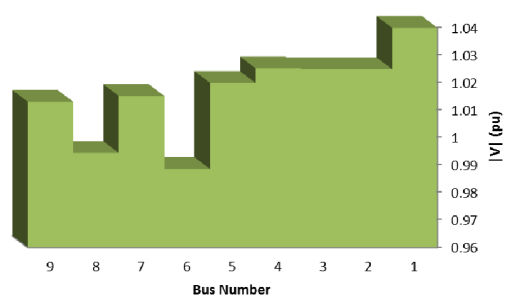

Fig. 6. Voltage buses in the bus 5 with STATCOM.
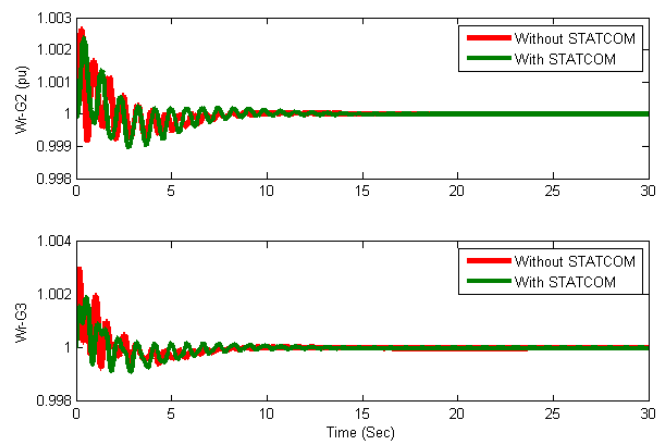

Fig. 7. Angular velocity of generators 2 and 3 with STATCOM (without controller). 


\section{Placing PSS}

Now PSS are added to generators 2 and 3 . The results of the simulation are presented in Figures 8 and 9. With the presence of PSS no change in network voltage profile is found. So the PSS in normal working condition has no effect on the parameters of the network such as voltage and therefore can't reduce network losses, and improve the lines capacity release. But, in the presence of PSS, rotor angular velocity fluctuations are reduced and damped with a better speed. In the case of a STATCOM connected to bus 5, rotor angular velocity damping in terms of time is improved. The PSS has better effect in this regard than the STATCOM.

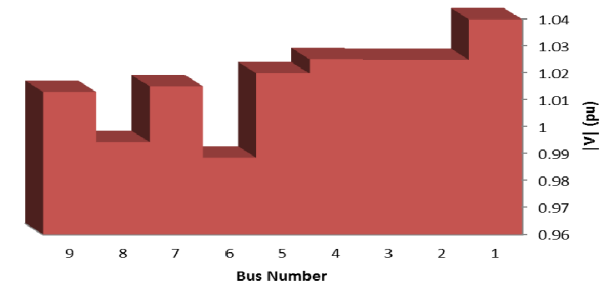

Fig. 8. The voltage buses with the presence of PSS
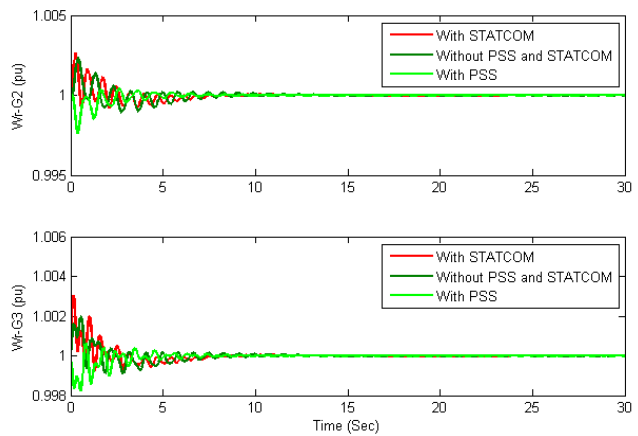

Fig. 9. The angular velocity of generators 2 and 3 according to time.

\section{Case of Circuit Fault without STATCOM or PSS}

In this case, the network is simulated under a three-phase short circuit fault of $200 \mathrm{~ms}$ ( 10 cycles, $50 \mathrm{~Hz}$ frequency) on the line between buses 5 and 7 (closer to bus 5). The results of this simulation without the presence of STATCOM and PSS are shown in Figures 10 and 11. When the fault occurs all buses experience a sharp drop and voltage did not recover after fault clearance. The 5 and 7 bus voltage, dropped more than other buses. It can be seen that the angular velocity fluctuations of the synchronous generators at the time of fault increased and after it was fixed, the time was spent for the damping of oscillations.

\section{E. Placing STATCOM}

The STATCOM is placed on bus 5. The controller is again the PI controller, with coefficients optimized by GA. The results of the simulation of STATCOM on bus 5 , in the presence of a short circuit fault are shown in Figures 22 and 33. Because of the presence of STATCOM at bus 5 and the reactive power injection to the network, all buses voltage consist of less drop and buses are shown to have the ability to restore the voltage. In Figure 13 we observe that with the presence of STATCOM, not only fluctuations in angular velocity generator have been dramatically reduced, but also the damping of fluctuations happened sooner.

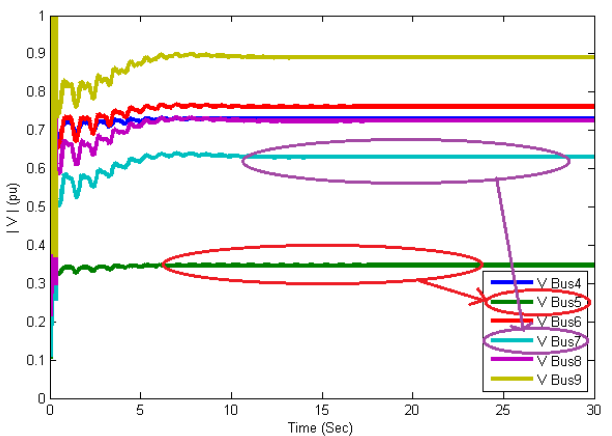

Fig. 10. The buses voltage in the presence of three-phase short circuit fault according to time (without PSS and STATCOM).
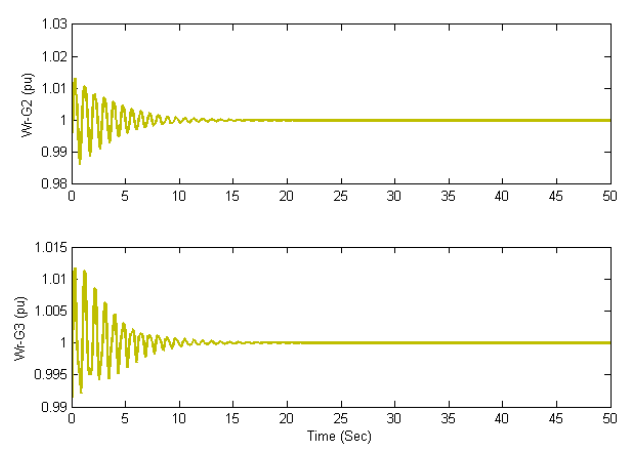

Fig. 11. Rotor angular velocity of generator (2) and (3) in the presence of three-phase short circuit fault according to time (without PSS and STATCOM).

\section{F. Placing PSS}

Next, instead of placing STATCOM in bus 5, according to different controllers (PD optimization and fuzzy control) [25], we will place PSS in generators 2 and 3 and compare the results. These results were compared in Figures 14-16. As shown in Figure 14, with the presence of PSS, the buses voltage during and after the error has not changed much and voltages in addition to a sharp drop in the voltage level during the fault, did not reach an acceptable level. In Figure 15 we observe that in the presence of optimized classic controllers, the impact of STATCOM in damping of oscillations in the angular velocity of the synchronous generators have been better than PSS. The results in Figure 16 show that with the presence of the intelligent controller, PSS performs better than STATCOM in terms of damping the frequency oscillations.

\section{CONCLUSION}

In this paper, the impact of STATCOM and PSS in power quality is studied. The 9 Bus-IEEE standard network was chosen as the test network and normal operation and operation during a fault scenarios were simulated in MATLAB. 


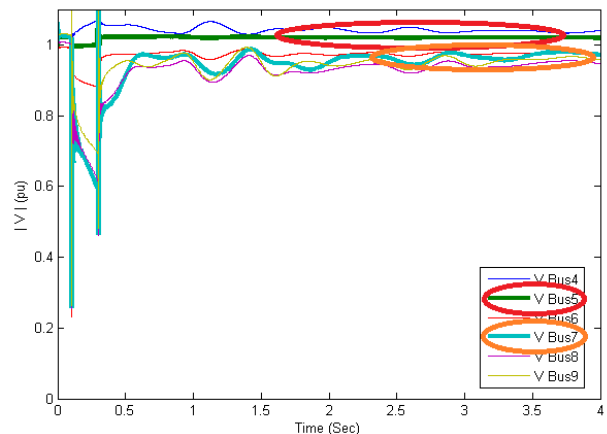

Fig. 12. The buses voltage in the presence of three-phase short circuit fault according to time (with STATCOM).
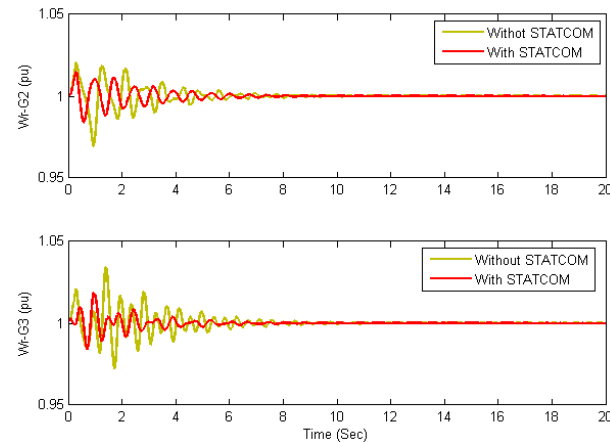

Fig. 13. Rotor angular velocity of generator (2) and(3) in the presence of three-phase short circuit fault according to time (with STATCOM).

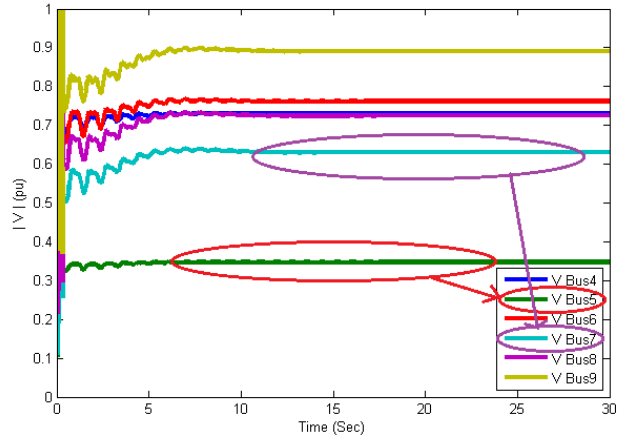

Fig. 14. The buses voltage in the presence of three-phase short circuit fault according to time (based on optimized PD controller for PSS).
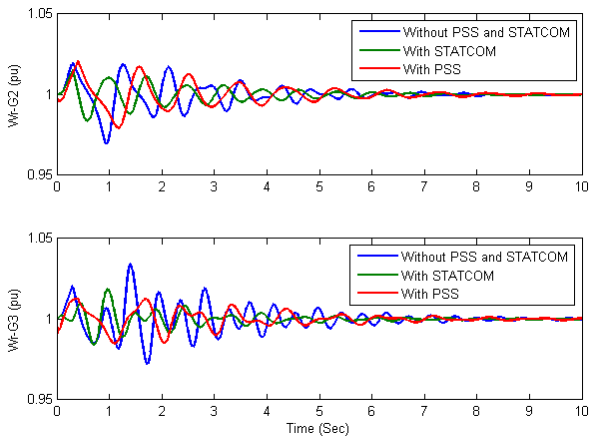

Fig. 15. Rotor angular velocity of generator (2) and (3) in the presence of three-phase short circuit fault according to time (based on optimized PD controller for PSS).
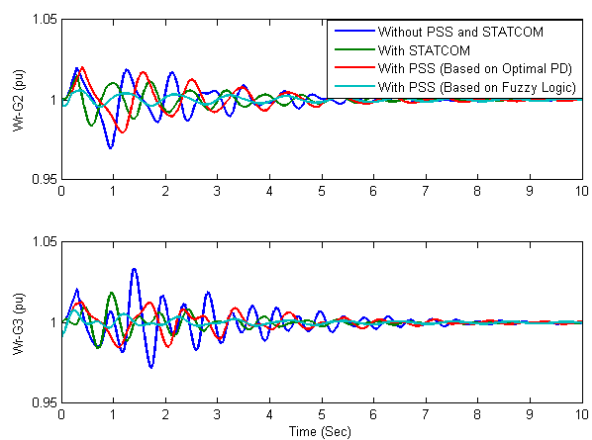

Fig. 16. Rotor angular velocity of generator (2) and (3) in the presence of three-phase short circuit fault according to time (based on optimized PD controller for PSS).

The results of the simulation showed that STATCOM was able to improve power quality in both cases. The PSS did not have a big impact in buses voltage stability improvement. However, it was effective in improving the damping of the oscillations frequency. It should be noted that according to the study results, it can be concluded that the type of controller used, had a great influence in achieving the desired goals. With the presence of the fuzzy controller, oscillations damping was better with PSS than what when PSS worked with an optimized PI controller.

\section{REFERENCES}

[1] M. Tavoosi, B. Fani, E. Adib, "Stability analysis and control of DFIG based wind turbine using FBC strategy", Journal of Intelligent Procedures in Electrical Technology, Vol. 4, No. 15, pp. 31-42, 2013

[2] M. Fooladgar, E. Rok-Rok, B. Fani, G. Shahgholian, "Evaluation of the trajectory sensitivity analysis of the DFIG control parameters in response to changes in wind speed and the line impedance connection to the grid DFIG", Journal of Intelligent Procedures in Electrical Technology, Vol. 5, No. 20, pp. 37-54, 2015

[3] G. Shahgholian, A. Movahedi, "Power system stabiliser and flexible alternating current transmission systems controller coordinated design using adaptive velocity update relaxation particle swarm optimisation algorithm in multi-machine power system", IET Generation, Transmission and Distribution, Vol. 10, No. 8, pp. 1860-1868, 2016

[4] G. Shahgholian, A. Movahedi, J. Faiz, "Coordinated design of TCSC and PSS controllers using VURPSO and genetic algorithms for multimachine power system stability", International Journal of Control, Automation, and Systems, Vol. 13, No. 2, pp. 398-409, 2015

[5] G. Shahgholian, M. Ebrahimi-Salary, "Effect of load shedding strategy on interconnected power systems stability when a blackout occurs", International Journal of Computer and Electrical Engineering, Vol. 4, No. 2, pp. 212-217, 2012

[6] G. Shahgholian, E. Mardani, M. Mahdavian, M. Janghorbani, M. Azadeh, S. Farazpey, "Impact of PSS and STATCOM on dynamic parameters of power system based on neuro-fuzzy controllers", 13th International Conference on Electrical Engineering/Electronics, Computer, Telecommunications and Information Technology (ECTICON), Chiang Mai, Thailand, pp. 1-6, 2016

[7] E. Behrouzian, M. Bongiorno, R. Teodorescu, "Impact of switching harmonics on capacitor cells balancing in phase-shifted PWM-based cascaded H-bridge STATCOM", IEEE Transactions on Power Electronics, Vol. 32, No. 1, pp. 815-824, 2017

[8] T. Fetouh, M. S. Zaky, "New approach to design SVC-based stabiliser using genetic algorithm and rough set theory", IET Generation, Transmission and Distribution, Vol. 11, No. 2, pp. 372-382, 2017

[9] G. Shahgholian, M. Mahdavian, M. Noorani-Kalteh, M. R. Janghorbani, "Design of a new IPFC-based damping neurocontrol for enhancing 
stability of a power system using particle swarm optimization", International Journal of Smart Electrical Engineering, Vol. 3, No. 2, pp. 73-78, 2014

[10] S. Shivam, I. Hussain, B. Singh, "Real-time implementation of SPV system with DSTATCOM capabilities in three-phase four-wire distribution system", IET Generation, Transmission and Distribution, Vol. 11, No. 2, pp. 495-503, 2017

[11] G. Shahgholian, B. Bayat, "A new control technique for improving the oscillations and decreasing the harmonic components of voltage in STATCOM", International Review of Electrical Engineering, Vol. 6, No. 6, pp. 3163-3174, 2011

[12] M. R. Tavana, M. H. Khooban, T. Niknam, "Adaptive PI controller to voltage regulation in power systems: STATCOM as a case study", ISA Transactions, Vol. 66, pp. 325-334, 2017

[13] G. Shahgholian, M. Maghsoodi, A. Movahedi, "Fuzzy proportional integral controller design for thyristor controlled series capacitor and power system stabilizer to improve power system stability", Revue Roumaine Des Sciences Techniques, Vol. 61, No. 4, pp. 418-423, 2016

[14] M. Bakhshi, M. H. Holakooie, A. Rabiee, "Fuzzy based damping controller for TCSC using local measurements to enhance transient stability of power systems", International Journal of Electrical Power and Energy Systems, Vol. 85, pp. 12-21, 2017

[15] B. Vijay Kumar, N. V. Srikanth, "A hybrid approach for optimal location and capacity of UPFC to improve the dynamic stability of the power system”, Applied Soft Computing, Vol. 52, pp. 974-986, 2017

[16] O. Ziaee, F. F. Choobineh, "Optimal location-allocation of TCSC devices on a transmission network", IEEE Transactions on Power Systems, Vol. 32, No. 1, pp. 94-102, 2017

[17] S. J. Galloway, I. M. Elders, G. M. Burt, B. Sookananta, "Optimal flexible alternative current transmission system device allocation under system fluctuations due to demand and renewable generation", IET Generation, Transmission and Distribution, Vol. 4, No. 6, pp. 725-735, 2010

[18] H. Ebrahimian, E. F. Sheikhahmad, "Wide-area based on coordinated tuning of fuzzy PSS and FACTS controller in multi-machine environment", Advances in Science and Technology Research Journal, Vol. 10, No. 29, pp. 85-96, 2016

[19] B. K. Kumar, S. N. Singh, S. C. Srivastava, "Placement of FACTS controllers using modal controllability indices to damp out power system oscillations", IET Generation, Transmission and Distribution,, Vol. 1, No. 2, pp. 209-217, 2007

[20] E. Ghahremani, I. Kamwa, "Optimal placement of multiple-type FACTS devices to maximize power system loadability using a generic graphical user interface", IEEE Transactions On Power Systems, Vol.28, No. 2, pp. 764-778, 2012

[21] M. Edrah, K. L. Lo, O. Anaya-Lara, "Impacts of high penetration of DFIG wind turbines on rotor angle stability of power systems", IEEE Transactions on Sustainable Energy, Vol. 6, No. 3, pp. 759-766, 2015
[22] Y. Xu, F. Li, "Adaptive PI control of STATCOM for voltage regulation", IEEE Transactions on Power Delivery, Vol. 29, No. 3, pp. $1002-1011,2014$

[23] L. M. Castro, E. Acha, C. R. Fuerte-Esquivel, "A novel STATCOM model for dynamic power system simulations", IEEE Transactions on Power Systems, Vol. 28, No. 3, pp. 3145-3154, 2013

[24] G. Shahgholian, J. Faiz, "Static synchronous compensator for improving performance of power system: A review", International Review of Electrical Engineering, Vol.5, No. 5, pp. 2333-2342, 2010

[25] R. K. Khadanga, J. K. Satapathy, "Time delay approach for PSS and SSSC based coordinated controller design using hybrid PSO-GSA algorithm", International Journal of Electrical Power and Energy Systems, Vol. 71, pp. 262-273, 2015

[26] B. S. Theja, A. Rajasekhar, A. Abraham, "An optimal design of coordinated PI based PSS with TCSC controller using modified Teaching learning based optimization", World Congress on Nature and Biologically Inspired Computing, pp. 99-106, Fargo, North Dakota, 2013

[27] G. Shahgholian, "Power system stabilizer application for load frequency control in hydro-electric power plant", Engineering Mathematics, Vol. 2, No. 1, pp. 21-30, 2017

[28] M. B. A. Jabali, M. H. Kazemi, "A new LPV modeling approach using PCA-based parameter set mapping to design a PSS", Journal of Advanced Research, Vol. 8, No. 1, pp. 23-32, 2017

[29] V. Keumarsi, M. Simab, G. Shahgholian, "An integrated approach for optimal placement and tuning of power system stabilizer in multimachine systems", International Journal of Electrical Power and Energy Systems, Vol. 63, pp. 132-139, 2014

[30] T. H. S. Bossa, N. Martins, R. J. G. da Silva, P. C. Pellanda, "A field test to determine PSS effectiveness at multigenerator power plants", IEEE Transactions on Power Systems, Vol. 26, No. 3, pp. 1522-1533, 2011

[31] M. T. Khosroshahi, F. M. Kazemi, M. R. Jannati-Oskuee, S. NajafiRavadanegh, "Coordinated and uncoordinated design of LFO damping controllers with IPFC and PSS using ICA and SFLA", Journal of Central South University, Vol. 22, No. 9, pp. 3418-3426, 2015

[32] G. Shahgholian, A. Movahedi, "Coordinated design of thyristor controlled series capacitor and power system stabilizer controllers using velocity update relaxation particle swarm optimization for two-machine power system stability", Revue Roumaine Des Sciences Techniques, Vol. 59, No. 3, pp. 291-301, 2014

[33] P. M. Anderson, A. A. Fouad, Power system control and stability, Wiley-IEEE Press, Second Edition, (ISBN: 978-0-471-23862-1), 2002

[34] Y. J. Lin, "Proportional plus derivative output feedback based fuzzy logic power system stabilizer", International Journal of Electrical Power and Energy Systems, Vol. 44, No. 1, pp. 301-307, 2013 